\title{
Does coping strategies have a significant relationship with quality of life among caregivers of chronic illness patients?
}

\author{
Merican Aren ${ }^{*} 1$, Nurlatifah Rahim ${ }^{2}$, Jati Kasuma ${ }^{3}$ \\ ${ }^{123}$ Universiti Malaysia Sarawak, Malaysia \\ ${ }^{*}$ Corresponding author, $\equiv$ e-mail: amerikan@fcs.unimas.my
}

\begin{abstract}
The present study aimed to investigate the coping strategies and quality of life among caregivers of chronic illness patients. The study was conducted among the caregivers from five (5) villages in Sibu District of Sarawak by using a survey research design. A total of sixty seven (67) participants were participated in this study. Two different instruments were used to measure different types of variables. Research data collected was tested and analyzed by using a descriptive statistic and Pearson Correlation. The result revealed that there was a significant relationship between the coping strategies and the quality of life among caregivers of chronic illness patients. The relationship between both coping strategies and domains of quality of life was in a moderate level. As an implication, counselors should be more aware of the types of coping strategies used by the caregivers because it can affect the individual's quality of life indirectly.
\end{abstract}

Keywords: Coping strategies, quality of life, caregivers, chronic illness, counselors

How to Cite: Aren, M., Rahim,N., \& Kasuma, J. (2017). Does coping strategies have a significant relationship with quality of life among caregivers of chronic illness patients. Couns-Edu: International Journal of Counseling and Education, 2(3): pp. 92-105. DOI:https://doi.org/10.23916/002017029430

\section{Introduction}

Chronic illnesses can be defined as illnesses that are prolonged, do not resolve spontaneously, are rarely cured completely, and may involve in some types of long-term disability that are irreversible (Sperry, Lewis, Carlson \& Englar-Calrson, 2005). There are more than 100 chronic illnesses but only five are quite common among adults in United States, which are Arthritis, Cardiovascular Disease, Cancer, Chronic Obstructive Lung Disease and Diabetes (National Center for Chronic Disease Prevention and Health Promotion, 2000). Patients with chronic illnesses often struggle with a decrease in their quality of life, a concomitant decrease in their overall functionality, and an increase in attempts to cope with a life which has often been prolonged. Coping with chronic illness can be a major challenge to the patient and his or her family. This situation can be even more challenging if the patient tries to cope with the illness over a long period (Compas, B. E., Jaser, S. S., Dunn, M. J., \& Rodriguez, E. M. 2012; Sadigh, M. R. 2012). According to Sperry, Lewis, Carlson \& Englar-Calrson (2005), patient with chronic illness may need assistance in making emotional, behavioral and social adaptations. It is proven that the interventions involving social support, improved self-efficacy, problem solving or coping skills have a positive impact or outcomes for chronic illness (Rotondi, A. J., Anderson, C. M., Haas, G. L., Eack, S. M., Spring, M. B., Ganguli, R., ... \& Rosenstock, J. 2010). 
Family members are typically referred to as 'informal caregivers' (Given, Given and Sherwood, 2012). The task of caregiving is probably not a simple task. Caregiver would have an additional responsibility in their lives; between managing other's life and their lives as well. Caregiving will occupy the caregiver's time, energy and attention which probably can reduce their quality of life; domains often included are physical, social and psychological domains. End-of-life care for many patients with advanced disease is provided at home by a family member who assumes and or coordinates the majority of care.

In the country, the increase in the rate of cancer has rose sharply with the large increase in the incidence as well as a mortality rate (mortality). A total of 21,773 cases of cancer among residents of Peninsular Malaysia in 2006 were registered with the Cancer Council of Malaysia, consists of 9974 cases in men and 11799 cases among women (Low, W. Y., Ng, C. J., Ng, C. W., Choo, W. Y., \& Tong, W. T. 2012). The types of cancer that top the list of highest number of cases are breast, colon, lung, and cervix. In general, caregivers' family represents a significant portion of the population.

National Surveys (2007) estimated that there were adults between 24 to 27.6 million providing care to a family member or friend with a chronic, disabling, or terminal illness. Statistics survey (2006) reported that approximately 2.7 million adults, or 1 in eight adults, were providing such care; between women aged of 45 and 64 , this number increased to 1 . Unfortunately, the stress of providing care often results in the caregivers' family as, they are experiencing elevated levels of emotional distress. The current study examined lifestyle interference as a possible factor contributing to emotional distress in caregivers (Mazanec, S. R., Daly, B. J., Douglas, S. L., \& Lipson, A. R. 2011; Adelman, R. D., Tmanova, L. L., Delgado, D., Dion, S., \& Lachs, M. S. 2014). Providing care can interfere with the caregiver's ability to participate in valued activities such as work, recreation and social outings, and this disruption to lifestyle, as shown in patient studies, can result in emotional distress. Cancer patients' caregivers may be affected by various stressors such as psychological, social, or physical health functioning (Bevans, M., \& Sternberg, E. M. 2012; Ownsworth, T., Henderson, L., \& Chambers, S. K. 2010). Behaviors such as diminished rest or exercise and neglecting their own due to care for a patient who has breast cancer, can influence their health and quality of life. On the other hand, caregiver's mentality and quality of life are significantly affected by a patient's stage of illness.

Caring for an ailing family member can be a great burden and is usually portrayed as such in public and private discourse. The care work in itself may be physically, mentally, and financially challenging. By caregiving a patient may also restrict the caregivers' participation in personal, family, and labor market activities. In addition, the caregiver may worry about the care recipient, their own ability to meet future care needs, and prospects of receiving public support. Not surprisingly therefore, much of the literature indicates that caregiving is associated with psychological distress (Hansen, T., Slagsvold, B., \& Ingebretsen, R. 2013; Bachner, Y. G., O'Rourke, N., \& Carmel, S. 2011).

Caregiving is an occupation that can be short-lived, or, with an increasingly chronically ill population, can last after many years. While making an important contribution to society by supporting the disabled persons at home, caregivers are making significant sacrifices, in order to care for relatives and friends (Sheets, C., \& Mahoney-Gleason, H. 2010; Pusey-Murray, A., \& Miller, P. 2013). In addition, so much of their energy and attention is directed toward their caregiving occupation, that it changes or diminishes their quality of life (Collins, Swartz, College, \& Jefferson, 2011). Reinhard, Given, Petlick and Bemis (2000) state that caregiver's burden and depressive symptoms are the most common negative outcomes of providing care for the elderly and chronically illness patients. Caregiver's burden is defined as the negative reaction as an impact in the caregiver's social, occupational, and personal roles and appears to be a precursor to depressive symptoms when providing a care period (King, B. A. 2015; Roach, L. V. (2013; Dawson, S. 2013). It is found that in further research is needed to identify further strategies to offset caregiver stress, depression, and poor health outcomes. (Collins, Swartz, College, \& Jefferson, 2011).

According to Ekwall, Sivberg and Hallberg (2007), higher quality of life were predicted by using self-sustaining coping strategies and high sense of coherence. In reducing the caregiver's burden and offset their stress, coping strategies are suggested ways because it can make life less overwhelming and easier to bear. In a conclusion, this research will be conducted to see how the caregivers' cope with their responsibilities which lead to their effectiveness quality of life. This study hopes to bridge that gap by 


\section{COUNS-EDU}

Vol.2, No.3, Month 2017

Available online: http://journal.konselor.or.id/index.php/counsedu

M. Aren, N. Rahim, \& Jati Kasuma

studying the coping strategies of caregivers in caregiving the patients with chronic illness and by identifying which coping strategies are effective and which is not and perhaps the relationship between the coping strategies and perceived quality of life among the caregivers of chronic illness patients. Thus, the purpose of this research is to identify the relationship between coping strategies of quality of life among caregivers of chronic illness patients.

\section{Concept of Coping Strategies}

The word's skill is often paired with coping, which shows an active process that can be learned. The word coping with itself is defined as thoughts and behavior used to manage the internal and external demands of situations that are appraised as stressful. There are three classic models introduced to explain aspects of coping skills which are appraisal-focused coping, problem-focused coping and emotion-focused coping (Hofseth, E. 2016; Xue, X. 2012; Russell, L. M. 2011). This model has been used in many research and modified. However, in this research, problem-focused coping and emotion-focused coping will be addressed.

\section{Problem focused coping}

Drench, Noonan, Sharby and Ventura (2012) states that problem-focused coping is the practical aspects of a situation and is directed in problem solving by hand and altering situation that client's view as controllable and can be amended. First, the problem must be identified, then followed by recognizing the alternative option for futher action. Next, the action that would be selected and implemented will be indentified (Mitchell, B. 2013; Krupka, E. L., \& Weber, R. A. 2013).

\section{Emotional-focused coping}

Emotional-focused coping involves in managing the emotions associated with a critical situation. These coping skill is used to reduce emotional distress and can make life less overwhelming and easier to bear (Drench, Noonan, Sharby and Ventura, 2012). In their research states that emotion-focused can be effective when an individual perceives that there is nothing that can be done to alter the stressor (Tenenbaum, L. S., Varjas, K., Meyers, J., \& Parris, L. 2011; Skinner, E. A., \& Zimmer-Gembeck, M. J. 2011).

\section{Caregivers}

Everyone can be a caregiver. Alecxih, Zeruld \& Olearczyk (n.d) states that based on the caregiver selfidentified process, the SIPP estimates that there are 9.4 million caregivers providing regular assistance for individuals of all ages. The research found that among the 9.4 million caregivers, 15 percent or nearly twothirds of caregivers are women and women are 1.8 times more likely to be caregivers' relative to men. Majority of the caregivers are women, approximately age 46, with some college education. Wolff and Kasper (2006) states that spouses also providive caregiving although the majority of family caregivers are adult children. Drench, Noonan, Sharby and Ventura (2012) in their research state that caregivers time commitments range from a few hours per week to 40 or more hours per week, essentially providing constant care.

Hebertz and Schulz (2006) in their research found that there are currently 44 million people, or $21 \%$ of the adult population aged 18 years or older, providing unpaid care to an ill or disabled family member. Seventy-nine percent of care recipients are 50 years of age or older (mean age, 75). This situation tends to become worst when at least 12 million people care for loved ones with serious limitations in activity that prevent them from attending school, work, or caring for themselves (Hebertz and Schulz, 2006) The typical caregiver with some college experience, provides more than 20 hours of care per week. According to Hebertz and Schulz (2006) Although the majority (61\%) are women, the numbers of male caregivers will likely increase as more women delay childbearing and enter the labor force. One report documents states a 50\% increased in men becoming the primary caregivers between 1984 and 1994. However, according to Hussain, Abdullah \& Esa (2014) states that out of 10 to $15 \%$ of 25.7 millions of Malaysians are caregivers by which it is common that family members provide most of the assistance in activities of daily living $(\mathrm{ADL})$. Caring for their sick family members has been a part of their roles and responsibilities. 


\section{Caregivers responsibilities}

Caregivers have many responsibilities. According to Stajduhar (2013) besides providing caregiving, caregiver family have many functions including, but not limited to, domestic chores and household tasks, providing personal care and assisting the dying person with activities of daily living. In caregiving the patients, caregiver family will manage symptoms such as pain and constipation, providing emotional and social support to the dying person, being a spokesperson, advocate and proxy decision maker and coordinating all aspects of the dying person's care (Stajduhar, 2013).

Reihard, Given, Petlick et al (2000) in their study states that caregivers spend a substantial amount of time interacting with their care recipients, while providing care in a wide range of activities. Caregiving can last for a short period of post acute care, especially after a hospitalization, to more than 40 years of ongoing care for a person with chronic care needs. On average, informal caregivers devote 4.3 years to this work. Four out of 10 caregivers spend 5 or more years providing support, and 2 out of 10 have spent a decade or more of their lives caring for their family member. This is a day-in, and day-out responsibility. More than half of caregivers' family provide eight hours of care or more every week, and one in five spends more than 40 hours per week (Olivares-Tirado, P., \& Tamiya, N. 2013; Lipton, A. M., \& Marshall, C. D. 2012; Bruhn, J. G., \& Rebach, H. M. 2014).

Reihard, Given, Petlick et al (2000; Petty, M. G. 2011; Mcghan, G. E. 2014) states that most researchers in the caregiving field conceptualize that family members assist in activities of daily living (ADLs) and instrumental activities of daily living (IADLs), but those concepts do not adequately capture the complexity and stressfulness of caregiving. For examples, assistance with bathing does not capture bathing a person who is resisting a bath. Helping with medications does not adequately capture the hassles of medication administration, especially when the care recipient is receiving multiple medications several times a day, including injections, inhalers, eye drops, and crushed tablets. The need to make decisions on behalf of family members who are unable to do so is stressful, as this is contrary to the caregivers' normal role, and they are concerned that the decisions are correct. Being responsible for medical and nursing procedures like managing urinary catheters, skin care around a central line, gastrostomy tube feedings, and ventilators is anxiety provoking for the novice nursing student, but it becomes a routine for the family of patients with chronic illnesses who are living at home (Strassburger, Z. 2016; Lewenson, S. B., \& TruglioLondrigan, M. 2014; Stanley, V. J. 2011).

Caregiver families are often to feel unprepared to provide care, have inadequate knowledge to deliver proper care, and receive little guidance from the formal health care providers (Feinberg, L., Reinhard, S. C., Houser, A., \& Choula, R. 2011; Kaakinen, J. R., Coehlo, D. P., Steele, R., Tabacco, A., \& Hanson, S. M. H. 2014; Brown, C. E., Jecker, N. S., \& Curtis, J. R. 2016). Nurses and caregivers' family are rarely agree about specific needs or problems during hospital admission or discharge, in part because nurses are often row be unaware of the strengths and weaknesses of both patient and caregiver. Due to inadequate knowledge and skill, family caregivers may be unfamiliar with the type of care that they must provide or the amount of care needed by the patient under their care (Linderholm, M., \& Friedrichsen, M. 2010; Stenberg, U., Ruland, C. M., \& Miaskowski, C. 2010; Dalvandi, A., Ekman, S. L., Khankeh, H. R., Maddah, S. S. B., Lutzen, K., \& Heikkilä, K. 2011). Family caregivers may not know when they need community resources, and then they may not know how toaccess and best utilize the available resources. As a result, caregivers often neglect their own health care needs in order to assist their family member, causing deterioration in the caregiver's health and well-being (Bauer, J. M., \& SousaPoza, A. 2015; Yang, X., Wang, L., He, J., Ge, C., Chang, Y., Fu, J., ... \& Zhou, Y. 2012).

While family caregiving has considerable rewards, including allowing caregivers to facilitate closure after death and helping them find meaning in their experiences, it is physically exhausting, difficult to recover from, and fraught with emotional and financial burdens (Stajduhar, K. I. 2013). Therefore, it is not surprising that the health and well-being of caregivers' family often suffer as well when they provide end of life care at home. 


\section{Method}

This research used two instruments which are Coping Strategies Inventory and Quality of Life Index. Self-administered questionnaires were distributed among the caregivers of chronic illness patients at 5 villages in Sibu District of Sarawak; namely caregivers in Kampung Bandong, Kampung Barieng, Kampung Nangka, Kampung Dato' and Kampung Hilir. The population from which the sample will be drawn is that the person (ages 20 to 50 years old) who provides caregiving which would be a family member or, less often, a friend. Other inclusion criteria that were considered in this research were caregivers who had provided the caregiving to the patient before and the caregiver that is still providing the caregiving to the patient. There are 125 houses involve in providing caregiving to chronic illness patients. Only one person from each house was required to participate in this research. Therefore, the minimum sample assumed for this research was 95 persons which 19 persons were involved in each village.

\section{Results and Discussions}

\section{Descriptive Statistic}

Based on Table 1, majority of the respondents were 42 females $(62.7 \%)$ and the rest of the respondents were 25 males $(37.3 \%)$. The total respondents involved in this study were 67 respondents.31of the respondents who participated in this study were in the range of 30 years old and above (46.3\%). There were only 11 respondents (16.4\%) were adolescents who aged 20 years old and below. The respondents who participated in this study weremultiracial. 34 respondents $(50.7 \%)$ were Malay, and 24 respondents (35.8\%) were Bumiputera Sarawak, mostly Melanau and Iban. There were only 9 respondents (13.4\%) who were Chinese. Finally, there was no Indian and Bumiputera Sabah participated in this study.

There were 44 respondents (65.7\%) who were unmarried and only 23 respondents $(34.3 \%)$ were married. For periods of caregiving, 37 of the respondents $(55.2 \%)$ had provided the caregiving less than 6 months to the patients. It was followed by $14(20.9 \%)$ respondents who provided caregiving in the range of 6 months to 1 year. 5 respondents (7.5\%) involved in caregiving for 1 to 2 years and 2 to 5 years respectively. Finally, there were only 6 respondents $(9.0 \%)$ had provided caregiving for 5 years and above. 
Table 1. Distribution of respondents based on demographic characteristic

\begin{tabular}{lcc}
\hline Demographic & Frequency & Percent (\%) \\
\hline Sex & 25 & \\
Male & 42 & 37.3 \\
Female & & 62.7 \\
Age & & \\
20 years old and below & 11 & 16.4 \\
11 to 29 years old & 25 & 37.3 \\
30 years old and above & 31 & 46.3 \\
& & \\
Race & 34 & 50.7 \\
Malay & 9 & 13.4 \\
Chinese & 0 & 0.0 \\
Indian & 24 & 35.8 \\
Bumiputera Sarawak & 0 & 0.0 \\
Bumiputera Sabah & & \\
Marriage Status & & \\
Single & 44 & 65.7 \\
Married & 23 & 34.3 \\
Periods of caregiving & & \\
Less than 6 months & 37 & 55.2 \\
6 months to 1 year & 14 & 20.9 \\
1 year to 2 years & 5 & 7.5 \\
2 years to 5 years & 5 & 7.5 \\
5 years and above & 6 & 9.0 \\
\hline \hline
\end{tabular}

Relationship with Problem-focused coping and health functioning domain

Based on Table 2, the result indicated that there is a moderate relationship between problem-focused coping and health functioning domain $(r=0.454$, $p$-value $=0.000)$. Hence, it can be concluded that there was a positive significant relationship between problem-focused coping and health functioning domain.

Table 2. Results of the correlation between problem-focused coping and health functioning domain

\begin{tabular}{llrr}
\hline \hline & & $\begin{array}{c}\text { Problem-focused } \\
\text { coping }\end{array}$ & \multicolumn{2}{c}{$\begin{array}{c}\text { Health functioning } \\
\text { domain }\end{array}$} \\
\hline \multirow{2}{*}{$\begin{array}{l}\text { Problem-focused } \\
\text { Coping }\end{array}$} & Pearson Correlation & 1 & $0.454^{* *}$ \\
& Sig. (2-tailed) & & 0.000 \\
& $\mathrm{~N}$ & 67 & 67 \\
\hline \multirow{2}{*}{$\begin{array}{l}\text { Health functioning } \\
\text { domain }\end{array}$} & Pearson Correlation & $0.454^{* *}$ & 1 \\
& Sig. (2-tailed) & 0.000 & 67 \\
\hline \hline
\end{tabular}

**. Correlation is significant at the 0.01 level (2-tailed). 


\section{COUNS-EDU}

Vol.2, No.3, Month 2017

Research had proven that the caregiving role have negative implications on the physical health of caregivers. In providing the caregiving, there will beinterference inthe caregivers' preventive health behaviors which in turn may impede a caregiver's ability to cope in caregiving role (Dupuis, Epp \& Smale, 2004). It was also proven in Lai (2012) which states that according to the caregivers, an overwhelming $99.1 \%$ of care receivers reported at least one type of major health problem or illness. Examples of major health problems within the sample of care receivers included problems with joints, the back, and arthritis (74.4\%); physical mobility problem (63.2\%); high blood pressure (46.6\%); eye problems (37.6\%); problems with hearing (36.8\%); heart disease (33.2\%); and problems with depression $(32.9 \%)$. Based on the result, using problem-focused coping will improve the caregivers' health related quality of life. The result was consistent to some literatures in which according to Ekwall, Sivberg \& Hallberg (2006), almost 70\% of caregivers provided help every day. Higher health-related quality of life was predicted by using selfsustaining coping strategies and by highsense of coherence.

\section{Relationship between problem-focused coping and psychological or spiritual domain}

Based on Table 3, the result indicated that there is a moderate relationship between problem-focused coping and psychological or spiritual domain $(r=0.462, p$-value $=0.000)$. The significance value was smaller than the alpha value $(\alpha),(p<0.01)$. Hence, it can be concluded that there was a significant positive relationship between problem-focused coping and psychological or spiritual domain

Table 3. Correlation between problem-focused coping and psychological or spiritual domain

\begin{tabular}{|c|c|c|c|}
\hline & & $\begin{array}{l}\text { Problem-focused } \\
\text { coping }\end{array}$ & $\begin{array}{l}\text { Psychological/spiritual } \\
\text { domain }\end{array}$ \\
\hline \multirow{3}{*}{$\begin{array}{l}\text { Problem-focused } \\
\text { Coping }\end{array}$} & Pearson Correlation & 1 & $0.462^{* *}$ \\
\hline & Sig. (2-tailed) & & 0.000 \\
\hline & $\mathrm{N}$ & 67 & 67 \\
\hline \multirow{3}{*}{$\begin{array}{l}\text { Psychological/ } \\
\text { spiritual domain }\end{array}$} & Pearson Correlation & $0.462^{* *}$ & 1 \\
\hline & Sig. (2-tailed) & 0.000 & \\
\hline & $\mathrm{N}$ & 67 & 67 \\
\hline
\end{tabular}

The result of the findings showed that when the caregivers practiced the problem-focused coping in providing caregiving, it improved the spiritual well-being in which the spiritual well-being is best defined as a state of being, reflecting positive feelings, behaviors that in turn provide the individual with positive attitudes, harmony and direction of life (Amjad \& Bokharey, 2014). However, the result is parallelwith the findings by which suggested that spirituality is associated with the acquisition of adaptive coping strategies

\section{Relationship between problem-focused coping and social and economic domain}

Result on Table 4 indicated that there is a weak relationship between problem-focused coping and social and economic domain $(r=0.339, p$-value $=0.000)$. The significance value was smaller than the alpha value $(\alpha), \quad(p<0.01)$.The National Survey (2007) stated that caregiving had effected in their overall financialsituation with nearly half (43\%) reports had increased financial worries and 53\% reports had been no change in their financial concerns when caregiving patients with chronic illnesses. 
Table 4. Correlation between problem-focused coping and social and economic domain

\begin{tabular}{llrr}
\hline \hline & & $\begin{array}{c}\text { Problem-focused } \\
\text { coping }\end{array}$ & $\begin{array}{c}\text { Social and economic } \\
\text { domain }\end{array}$ \\
\hline Problem-focused & Pearson Correlation & 1 & $0.339^{* *}$ \\
coping & Sig. (2-tailed) & 67 & 0.005 \\
& $\mathrm{~N}$ & $0.339^{* *}$ & 67 \\
\hline \multirow{2}{*}{$\begin{array}{l}\text { Social and economic } \\
\text { domain }\end{array}$} & Pearson Correlation & 0.005 & 1 \\
& Sig. (2-tailed) & 67 & 67 \\
\hline \hline & $\mathrm{N}$ & $* *$ Correlation is significant at the 0.01 level (2-tailed).
\end{tabular}

Lai (2012) in his research also states that while providing the caregiving, it impacted the economic quality of life of the caregivers. The results of the individual's items indicated $40 \%$ of the family caregivers indicated that they and their families could not afford those little extras because of the expenses to care for the care receiver. Another similar proportion (36.8\%) of the caregivers indicated that caring for the care receiver was too expensive. Hence, it can be concluded that while providing the caregiving, economic is a big matter for the caregivers.

\section{Relationship betweenproblem-focused coping and family relationship domain}

Based on Table 5, the result indicated that there is a very weak relationship between problem-focused coping and social and economic domain $(r=0.227, p$-value $=0.065)$. The significance value was greater than the alpha value $(\alpha),(p<0.05)$. Sanders (2003) states that family caregivers, is the first line of support to an elder in need from the beginning phase of caregiving to the transition phase of caregiving. The stress of caregiving, the need for decision-making, and the conflicts that might arise can affect the relationships of the caregiver with both the elder receiving care and with the other family members. Conflicts involving family members' attitudes and action towards the caregivers are associated with increased risk of depression among caregivers. By strengthening the quality of family interaction both reduces the stress and increases the rewards of caregiving. Hence, unfriendly and poor relationship can lead to greater stress, poorer care, and an increased likelihood of abuse and neglect.

Table 5. Correlation between problem-focused coping and family relationship domain

\begin{tabular}{llrr}
\hline \hline & & $\begin{array}{c}\text { Problem-focused } \\
\text { coping }\end{array}$ & $\begin{array}{c}\text { Family/Relationship } \\
\text { domain }\end{array}$ \\
\hline \multirow{2}{*}{$\begin{array}{l}\text { Problem-focused } \\
\text { coping }\end{array}$} & Pearson Correlation & 1 & 0.227 \\
& Sig. (2-tailed) & & 0.065 \\
Family/Relationship & $\mathrm{N}$ & 67 & 67 \\
domain & Pearson Correlation & 0.227 & 1 \\
& Sig. (2-tailed) & 0.065 & 67 \\
\hline \hline
\end{tabular}

Based on Table 5, result showed using the problem-focused coping strategies seemed to not improve the family related quality of life. It was consistent with a literature in which according to Ratanen, Mauno, Kinnunen \& Rantanen (2011) in their research states that they did not find any direct association between problem-focused coping and family satisfaction because well-being in the family domain depends more on the family. Besides that, another contributor that led to this result was most of the respondents of this research were unmarried. Based on the observation, the unmarried respondents tend to ignore the questions regarding the family related quality of life. Hence, the result was lower compared to other domain. 


\section{Relationship between emotion-focused coping and health functioning domain}

Table 6. Correlation between emotion-focused coping and health functioning domain

\begin{tabular}{|c|c|c|c|}
\hline & & $\begin{array}{l}\text { Emotion-focused } \\
\text { coping } \\
\end{array}$ & Health functioning domain \\
\hline \multirow{3}{*}{ Emotion-focused coping } & Pearson Correlation & 1 & $0.310^{*}$ \\
\hline & Sig. (2-tailed) & & 0.011 \\
\hline & $\mathrm{N}$ & 67 & 67 \\
\hline \multirow{3}{*}{$\begin{array}{l}\text { Health functioning } \\
\text { domain }\end{array}$} & Pearson Correlation & $0.310^{*}$ & 1 \\
\hline & Sig. (2-tailed) & 0.011 & \\
\hline & $\mathrm{N}$ & 67 & 67 \\
\hline
\end{tabular}

Relationship between emotion-focused coping and psychological o spiritual domain

Pearson Correlation was used to determine the relationship between types of coping strategies and domains of quality of life among caregivers of chronic illness patients. Based on the Table 7, the result indicated that there is a weak relationship between emotion-focused coping and psychological/spiritual domain $(r=0.304$, p-value $=0.012)$.

Table 7. Correlation between emotion-focused coping and psychological/spiritual domain

\begin{tabular}{llrr}
\hline \hline & & $\begin{array}{c}\text { Emotion-focused } \\
\text { Coping }\end{array}$ & $\begin{array}{c}\text { Psychological or spiritual } \\
\text { domain }\end{array}$ \\
\hline \multirow{2}{*}{$\begin{array}{l}\text { Emotion-focused } \\
\text { coping }\end{array}$} & Pearson Correlation & 1 & $0.304^{*}$ \\
& Sig. (2-tailed) & & 0.012 \\
Psychological/ & $\mathrm{N}$ & 67 & 67 \\
spiritual domain & Pearson Correlation & Sig. (2-tailed) & $0.304^{*}$ \\
& $\mathrm{~N}$ & 0.012 & 1 \\
\hline \hline
\end{tabular}

*. Correlation is significant at the 0.05 level (2-tailed).

\section{Relationship between emotion-focused economic domain}

Pearson Correlation was used to determine the relationship between types of coping strategies and domains of quality of life among caregivers of chronic illness patients

Table 8. Correlation between emotion-focused coping and social and economic domain

\begin{tabular}{llrr}
\hline \hline & & $\begin{array}{c}\text { Emotion-focused } \\
\text { coping }\end{array}$ & $\begin{array}{c}\text { Social and economic } \\
\text { domain }\end{array}$ \\
\hline Emotion-focused & Pearson Correlation & 1 & $0.482^{* *}$ \\
Coping & Sig. (2-tailed) & & 0.000 \\
& $\mathrm{~N}$ & 67 & 67 \\
Social and economic & Pearson Correlation & $0.482^{* *}$ & 1 \\
domain & Sig. (2-tailed) & 0.000 & 67 \\
& $\mathrm{~N}$ & 67 & 67 - Correlation is significant at the 0.01 level (2-tailed).
\end{tabular}




\section{Relationship between emotion-focused coping and family relationship domain}

Pearson Correlation was used to determine the relationship between types of coping strategies and domains of quality of life among caregivers of chronic illness patients. Based on Table 9, the result indicates that there is a very weak relationship between emotion-focused coping and family/relationship domain $(r=0.220$, $p$-value $=0.073)$. The significance value was greater than the alpha value $(\alpha),(p<0.01)$.

Table 9. Correlation between emotion-focused coping and family relationship domain

\begin{tabular}{llrr}
\hline \hline & & $\begin{array}{c}\text { Emotion-focused } \\
\text { coping }\end{array}$ & \multicolumn{2}{c}{$\begin{array}{c}\text { Family/Relationship } \\
\text { domain }\end{array}$} \\
\hline Emotion-focused & Pearson Correlation & 1 & 0.220 \\
Coping & Sig. (2-tailed) & & 0.073 \\
& $\mathrm{~N}$ & 67 & 67 \\
Family/Relationship & Pearson Correlation & 0.220 & 1 \\
domain & Sig. (2-tailed) & 0.073 & \\
& $\mathrm{~N}$ & 67 & 67 \\
\hline \hline
\end{tabular}

Hence, it can be concluded that there isno significant relationship between emotion-focused coping and family/relationship domain.According to Ratanen, Mauno, Kinnunen \& Rantanen (2011) in their research states that they did not find any direct association between emotion-focused coping and family satisfaction because well-being in the family domain depends more on family. Moreover, emotion-focused coping was also seen as the harmful coping strategy in a high family conflict in terms of family satisfaction.

\section{Relationshipbetween problem-focused coping and total quality of life among caregivers of chronic illness patients}

Pearson Correlation was used to determine the relationship between types of coping strategies and total quality of life among caregivers of chronic illness patients. Based on table 10, the result indicated that there is a moderate strong relationship between problem-focused coping and total quality of life $(\mathrm{r}=0.425, \mathrm{p}$ value $=0.000)$. The significance value was smaller than the alpha value $(\alpha),(p<0.01)$.

Table 10. Correlation between problem-focused coping and total quality of life

\begin{tabular}{llrr}
\hline \hline & & $\begin{array}{c}\text { Problem-focused } \\
\text { coping }\end{array}$ & \multicolumn{2}{c}{ Total Quality of Life } \\
\hline Problem-focused & Pearson Correlation & 1 & $0.425^{\text {** }}$ \\
coping & Sig. (2-tailed) & & 0.000 \\
& $\mathrm{~N}$ & 67 & 66 \\
\multirow{3}{*}{ Total Quality of Life } & Pearson Correlation & $0.425^{* *}$ & 1 \\
& Sig. (2-tailed) & 0.000 & \\
& $\mathrm{~N}$ & 66 & 66 \\
\hline \hline
\end{tabular}

**. Correlation is significant at the 0.01 level (2-tailed).

Hence, it can be concluded that there isa significant relationship between problem-focused coping and total quality of life.Problem-focused coping is defined as task-focused coping seeks to actively perform a task that will remove the problem or make the problem better; typically, if the frequency of task-focused coping increases, the distress decreases. Coping styles of caregivers are important determinants for their own psychosocial functioning, but not for the patients. To enhance caregivers' psychosocial functioning, rehabilitation should focus on changing their coping styles into ones that are less passive (Gregório, Stapert, Brands \& Heugten, 2011). Furthermore, distinct or additional interventions may be needed to change the patient's coping style. When task-oriented strategies is used and a positive attitude is maintained, it can lead to higher ratings of quality of life than those who use coping approach through 
being emotionally pre-occupied or using a passive, self-comforting approach. (The Parkinson Alliance's Coping Report, n.d).

\section{Relationship between emotion-focused coping and total quality of life among caregivers of chronic illness patients}

Based on Table 11, the result indicated that there is a weak relationship between emotion-focused coping and total quality of life $(\mathrm{r}=0.362$, $\mathrm{p}$-value $=0.000)$. The significance value was smaller than the alpha value $(\alpha),(p<0.01)$. Thus, the null hypothesis could be rejected. Hence, it can be concluded that there isa significant relationship between emotion-focused coping and total quality of life. Emotion-focused coping is used to regulate the emotion.

Table 11. Correlation between emotion-focused coping and total quality of life

\begin{tabular}{llrr}
\hline \hline & & $\begin{array}{l}\text { Emotion-focused } \\
\text { coping }\end{array}$ & \multicolumn{2}{c}{ Total Quality of Life } \\
\hline Emotion-focused & Pearson Correlation & 1 & $0.362^{* *}$ \\
coping & Sig. (2-tailed) & & 0.003 \\
& $\mathrm{~N}$ & 67 & 66 \\
& Pearson Correlation & $0.362^{* *}$ & 1 \\
Total Quality of Life & Sig. (2-tailed) & 0.003 & 66 \\
& $\mathrm{~N}$ & \multicolumn{2}{c}{66} \\
\hline \hline
\end{tabular}

This result is inconsistent with the The Parkinson Alliance's Coping Report (n.d) states that individuals who were emotionally preoccupied or who used passive, comfort-seeking coping techniques were negatively related to quality of life. In otherwords, people who were emotionally preoccupied or those who used a more passive approach to coping tended to report lower levels of quality of life. However, the present study shows that when the caregivers used the emotion-focused coping, the quality of life increases but in a moderate way. Besides that, the result was also inconsistent with research by Panthess, Kritpracha and Chinnawong (2011) which stated that emotion-focused coping strategy had a non-significant relationship with both overall quality of life and each dimension of quality of life. However, the research was conducted among the patients of Myocardial Infarction.

For our knowledge, this is the first study to report about the relationship between coping strategies and quality of life in Malaysia, especially in Sarawak. Hence, the results of this study can be considered as preliminary information, but they are sufficiently indicative of the importance of assessment of coping strategies by health care professionals.

\section{Conclusions}

This study showed that there was a positive significant relationship between both types of coping strategies (problem-focused coping and emotion-focused coping) and health functioning domain, psychological or spiritual domain and social and economic domain of quality of life. This study also showed a positive significant relationship between both types of coping strategies and total quality of life among caregivers of chronic illness patients. Caregivers himself or herself must recognize the importance of better quality of life. They need to understand that sometime problems that they face can affect their quality of life indirectly if they do not have proper coping strategies. The caregivers also must be provided with support in terms of guidance for the usage of proper coping strategies. Psycho education can be provided as well so that they will have the knowledge of how to cope to certain situation.Guidance from the counseling practitioners can be the key in helping the caregivers to achieve better quality of life. This is because when the caregivers encountered problems or issues in their life, counselors can be the person who they can rely for guidance. If needed,counseling practitioners may provide intervention to the caregivers on ways to cope with situations as the coping strategies is associated to better the quality of life. 


\section{References}

Adelman, R. D., Tmanova, L. L., Delgado, D., Dion, S., \& Lachs, M. S. (2014). Caregiver burden: a clinical review. Jama, 311(10), 1052-1060.

Amjad, F., \& Bokharey, I. Z. (2014). The Impact of Spiritual Wellbeing and Coping Strategies on Patients with Generalized Anxiety Disorder. Journal of Mental Health Muslim. 8(1). 21-37

Bachner, Y. G., O'Rourke, N., \& Carmel, S. (2011). Fear of death, mortality communication, and psychological distress among secular and religiously observant family caregivers of terminal cancer patients. Death Studies, 35(2), 163-187.

Bauer, J. M., \& Sousa-Poza, A. (2015). Impacts of informal caregiving on caregiver employment, health, and family. Journal of Population Ageing, 8(3), 113-145.

Bevans, M., \& Sternberg, E. M. (2012). Caregiving burden, stress, and health effects among family caregivers of adult cancer patients. Jama, 307(4), 398-403.

Brown, C. E., Jecker, N. S., \& Curtis, J. R. (2016). Inadequate palliative care in chronic lung disease. An issue of health care inequality. Annals of the American Thoracic Society, 13(3), 311-316.

Bruhn, J. G., \& Rebach, H. M. (2014). The sociology of caregiving. Springer.

Collins, L. G., \& Swartz, K. (2011). Caregiver care. American family physician, 83(11), 1309.

Compas, B. E., Jaser, S. S., Dunn, M. J., \& Rodriguez, E. M. (2012). Coping with chronic illness in childhood and adolescence. Annual review of clinical psychology, 8, 455-480.

Dalvandi, A., Ekman, S. L., Khankeh, H. R., Maddah, S. S. B., Lutzen, K., \& Heikkilä, K. (2011). Lack of continuity of rehabilitation care for stroke survivors: Iranian family caregivers' experience. Middle East Journal of Age \& Ageing, 8(4).

Dawson, S. (2013). Self-care for caregivers of adults with ASD: An Adlerian support group. Saint Mary's College of California.

Drench, M. E., Noonan, A, C., Sharby, N., \& Ventura, S, H. (2012). Psychological Aspects of Health Care (3rd ed.). United States of America: Pearson.

Dupuis, S. L., Epp, T., Smale, B. (2004). Caregivers of Persons with Dementia: Roles, Experiences, Supports and Caring. A Literatue Review. 1-74.

Ekwall, A. K., Sivberg, B., \& Hallberg, I. R. (2007). Older caregivers' coping strategies and sense of coherence in relation to quality of life: JAN Original Research. doi:10.1111/j.13652648.2006.03994.x

Feinberg, L., Reinhard, S. C., Houser, A., \& Choula, R. (2011). Valuing the invaluable: 2011 update, the growing contributions and costs of family caregiving. Washington, DC: AARP Public Policy Institute, 32 .

Given, B. A., Given, C. W., \& Sherwood, P. (2012, November). The challenge of quality cancer care for family caregivers. In Seminars in oncology nursing (Vol. 28, No. 4, pp. 205-212). WB Saunders.

Gregório, G. W., Stapert, S., Brands, I., \& Heugten, C. Van. (2011). Coping styles within the family system in the chronic phase following acquired brain injury : its relation to families' and patients' functioning: Original Report. (12), 190-196. doi:10.2340/16501977-0633

Hansen, T., Slagsvold, B., \& Ingebretsen, R. (2013). The strains and gains of caregiving: an examination of the effects of providing personal care to a parent on a range of indicators of psychological well-being. Social indicators research, 114(2), 323-343.

Hebert, R. S., Schulz, R., \& Ph, D. (2006). Caregiving at the end of life. Palliative Care Reviews ,9(5), 1174-1187.

Hofseth, E. (2016). Stress, emotions, and coping in elite football players: a study of negative emotions, defensive self-presentation strategies, and their relationships to skill and performance level.

Hussain, N. A., Abdullah, M. R., \& Esa, A. R. (2014). Predictors Of Life Satisfaction Among Family Caregivers Of Hospitalized First-Ever Stroke Patients In Kelantan. Asian Journal Psychiatry, 15, 164175.

Kaakinen, J. R., Coehlo, D. P., Steele, R., Tabacco, A., \& Hanson, S. M. H. (2014). Family health care nursing: Theory, practice, and research. FA Davis.

King, B. A. (2015). Grief Experience among Family Caregivers following Traumatic Brain Injury: The Role of Survivor Personality Change, Perceived Social Support, and Meaning Reconstruction.

Krupka, E. L., \& Weber, R. A. (2013). Identifying social norms using coordination games: Why does dictator game sharing vary?. Journal of the European Economic Association, 11(3), 495-524. 
Lai, D. W. L. (2012). Effects of Financial Costs on Caregiving Burden of Family Caregivers of Older Adults. Sage Open. 1-14. DOI: 10.1177/2158244012470467 http://sgo.sagepub.com

Lewenson, S. B., \& Truglio-Londrigan, M. (2014). Decision-making in nursing. Jones \& Bartlett Publishers.

Linderholm, M., \& Friedrichsen, M. (2010). A desire to be seen: Family caregivers' experiences of their caring role in palliative home care. Cancer nursing, 33(1), 28-36.

Lipton, A. M., \& Marshall, C. D. (2012). The common sense guide to dementia for clinicians and caregivers. Springer Science \& Business Media.

Low, W. Y., Ng, C. J., Ng, C. W., Choo, W. Y., \& Tong, W. T. (2012). 11 Learning from the past. Health Transitions and the Double Disease Burden in Asia and the Pacific: Histories of Responses to NonCommunicable and Communicable Diseases, 197.

Mazanec, S. R., Daly, B. J., Douglas, S. L., \& Lipson, A. R. (2011). Work productivity and health of informal caregivers of persons with advanced cancer. Research in nursing \& health, 34(6), 483-495.

Mcghan, G. E. (2014). Caregiver Outcomes and the Impact of Resources for Family Members Providing Care to Community Dwelling Older Adults.

Mitchell, B. (2013). Resource \& environmental management. Routledge.

National Center for Chronic Disease Prevention and Health Promotion (2000). Chronic Disease and their risk factor: The nation's leading causes of death, 1999. Washington, DC: Author.

National Survey (2007). Caregivers- What they spend, what they sacrifice: Evercare, 1987. Minnetonka, $\mathrm{MN}$

Olivares-Tirado, P., \& Tamiya, N. (2013). Trends and Factors in Japan's Long-Term Care Insurance System: Japan's 10-year Experience. Springer Science \& Business Media.

Ownsworth, T., Henderson, L., \& Chambers, S. K. (2010). Social support buffers the impact of functional impairments on caregiver psychological well- being in the context of brain tumor and other cancers. Psycho- Oncology, 19(10), 1116-1122.

Panthess, B., Kritpracha, C., \& Chinnawong, T. (2011). Correlation between Coping Strategies and Quality of Life among Myocardial Infarction Patients in Nepal. Nurse Media Journal of Nursing, $1(2), 187-194$

Petty, M. G. (2011). Left ventricular assist device therapy: Family caregivers' stress, perceived burden and quality of life. University of Minnesota.

Pusey-Murray, A., \& Miller, P. (2013). 'I need help': caregivers' experiences of caring for their relatives with mental illness in Jamaica. Mental health in family medicine, 10(2), 113.

Ratanen, M., Mauno, S., Kinnunen, U., \& Rantanen, J., (2011). Do Individual Coping Strategies Help or Harm in the Work-Family Conflict Situation? Examining Coping as a Moderator Between WorkFamily Conflict and Well-Being. International Journal of Stress Management. 18(10, 24-48

Reinhard, S. C., Given, B., Petlick, N. H., \& Bemis, A. (2000). Chapter 14 . Supporting Family Caregivers in Providing Care. Patient Safety and Quality: An Evidence-Based Handbook for Nurses.

Roach, L. V. (2013). Guilt, dysfunctional thought processes and depression in caregivers of people with dementia.

Rotondi, A. J., Anderson, C. M., Haas, G. L., Eack, S. M., Spring, M. B., Ganguli, R., ... \& Rosenstock, J. (2010). Web-based psychoeducational intervention for persons with schizophrenia and their supporters: one-year outcomes. Psychiatric Services, 61(11), 1099-1105.

Russell, L. M. (2011). High risk occupations: Employee stress and behavior under crisis. University of North Texas.

Sadigh, M. R. (2012). Autogenic Training: A Mind-Body Approach to the Treatment of Chronic Pain Syndrome and Stress-Related Disorders. McFarland.

Sanders, G. (2003). Family Relations and caregiving. The journey through caregiving. 1-21

Sheets, C., \& Mahoney-Gleason, H. (2010). Caregiver support in the Veterans Health Administration: caring for those who care. Generations, 34(2), 92-98.

Sperry, L., Lewis, J., Carlson, J., \& Englar-Carlson, J. (2005). Health Promotion and Health Counseling: Effective Counselling and Psychotherapeutic Strategies. (2nd ed.). United States of America: Pearson Education.

Stajduhar, K. I. (2013). Burdens of family caregiving at the end of life. Clinical \& Investigative Medicine, $36(3), 121-126$.

Stanley, V. J. (2011). Decision-Making Processes of Primary Informal Caregivers Regarding Care Recipients' Moves to Memory Care. 
Stenberg, U., Ruland, C. M., \& Miaskowski, C. (2010). Review of the literature on the effects of caring for a patient with cancer. Psycho- oncology, 19(10), 1013-1025.

Strassburger, Z. (2016). Medical Decision Making for Youth in the Foster Care System, 49 J. Marshall L. Rev. 1103 (2016). The John Marshall Law Review, 49(4), 5.

Tenenbaum, L. S., Varjas, K., Meyers, J., \& Parris, L. (2011). Coping strategies and perceived effectiveness in fourth through eighth grade victims of bullying. School Psychology International, 32(3), 263-287.

The Parkinson Alliance's Coping Report (n.d). Differential Impact of Coping Styles on Quality of Life for Individuals. DBS-STN.org. 1-9.

Wolff, J. and Kasper, J., "Caregivers of Frail Elders: Up- dating a National Profile," Gerontologist, Vol. 46, No. 3, 2006, pp. 344-356. http://dx.doi.org/10.1093/geront/46.3.344.

Xue, X. (2012). Career behaviors of tourism management students in China (Doctoral dissertation, Kent State University).

Yang, X., Wang, L., He, J., Ge, C., Chang, Y., Fu, J., ... \& Zhou, Y. (2012). Factors related to depressive symptoms among Chinese caregivers of cancer patients. Psycho- Oncology, 21(10), 1063-1070. 